\title{
The technical demands of amateur boxing: Effect of contest outcome, weight and ability
}

\author{
Edward Thomson ${ }^{1}$ and Kevin Lamb ${ }^{1}$ \\ ${ }^{1}$ Faculty of Science \& Engineering, Department of Sport and Exercise Sciences, University \\ of Chester, Chester Campus, Parkgate Road, Chester, Cheshire, CH1 4BJ.
}

\begin{abstract}
As research to-date has typically considered the technical features of amateur boxing performance with respect to contest outcome only, this study examined the offensive and defensive technical demands with respect to the independent and interactive effects of contest outcome, weight class and ability. Appraising eight offensive and four defensive actions and their corresponding outcomes (successful/unsuccessful), the technical demands of competitive boxing from 84 English amateurs (age: $21.3 \pm 3.1$ y; body mass: $68.1 \pm 11.4 \mathrm{~kg}$ ) across 11 weight categories (48 - 91+ kg) and two standards of competition (regional and national) were notated using computerized software. Data analysis reinforced that amateur boxing produces high technical loads (e.g. $~ 25$ punches and $~ 10$ defences per minute) and that performance is influenced significantly by the study's independent variables. In particular, boxing standard (ability) was positively associated with external load (frequency of offensive and defensive actions), and winning was associated with high offensive and low defensive frequencies, whereas weight class had an inconsistent impact on technical performance. It is recommended that appraisals of performance and approaches to training and competition should take heed of our observations and that future research considers the role of other independent variables, including opposition quality and 'style', likely to affect boxing performance.
\end{abstract}

Keywords: Combat sports, situational variables, notational analysis 


\title{
The technical demands of amateur boxing: Effect of contest outcome, weight and ability
}

\begin{abstract}
As research to-date has typically considered the technical features of amateur boxing performance with respect to the independent influence of contest outcome only, this study examined the offensive and defensive technical demands with respect to the independent and interactive effects of contest outcome, weight class and ability. Appraising eight offensive and four defensive actions and their corresponding outcomes (successful/unsuccessful), the technical demands of competitive boxing from 84 English amateurs (age: $21.3 \pm 3.1 \mathrm{y}$; body mass: 68.1 $\pm 11.4 \mathrm{~kg})$ across 11 weight categories $(48-91+\mathrm{kg})$ and two standards of competition (regional and national) were notated using computerized software. Data analysis reinforced that amateur boxing produces high technical loads (e.g. $\sim 25$ punches and $\sim 10$ defences per minute) and that performance is influenced significantly by the study's independent variables. In particular, boxing standard (ability) was positively associated with external load (frequency of offensive and defensive actions), and winning was associated with high offensive and low defensive frequencies, whereas weight class had an inconsistent impact on technical performance. It is recommended that appraisals of performance and approaches to training and competition should take heed of our observations and that future research considers the role of other independent variables, including opposition quality and 'style', likely to affect boxing performance.
\end{abstract}

Keywords: Combat sports, situational variables, notational analysis

\section{Introduction}


Whilst the sport of amateur boxing is popular both at national and international levels (Smith and Draper, 2007) there is a surprising shortage of sports science research describing its technical demands. Moreover, since its inception under the auspices of the International Olympic Committee in 1902, the sport has experienced several important rule changes relating to the method of judging, and the round and contest durations (Bianco et al., 2013) that have highlighted the scope to examine their impact on boxers' specific movements and actions during competition. Whilst such changes have likely affected the physical and physiological demands of the sport, our understanding of what characterises successful boxing remains rudimentary (Chaabène et al., 2015). Some previous research has attended to the numerous technical differences between winning and losing boxers (El-Ashker, 2011; Davis et al., 2013; Davis et al., 2015a; Davis et al., 2015b), but the studies appraised either novice or elite performances alone and there were clear concerns over the reliability and objectivity of their analysis procedures (O’Donoghue, 2007). Moreover, the designated 'winners' and 'losers' in these studies were not necessarily the same as those determined by the real-time judges, as victory was assigned by the analyst on the basis of the number of successful punches landed by each contestant. Indeed, the judges' decisions did not reflect the number of punches reported to have landed in a fifth of the male boxing contests (Davis et al., 2013a).

Whilst yet to be established, the technical profile of a typical winning or losing amateur boxing performance will no doubt vary according to the boxer's experience and ability. This is a reasonable assertion since lower ability (regional/inter-regional cf. 'novice' boxers) bouts are contested over eight minutes (three rounds, each two minutes [3x2 min], one minute rest intervals), usually within smaller boxing rings $\left(4.27 \mathrm{~m}^{2}\right.$ and $\left.4.88 \mathrm{~m}^{2}\right)$ than those of higher ability (national/international cf. 'open class'/'elite' boxers) bouts, which typically involve 
11-minute bouts (three rounds, each three minutes [3x3 min], one minute rest intervals) within larger rings (5.49 $\mathrm{m}^{2}$ and $6.1 \mathrm{~m}^{2}$ ). Additionally, a boxer's weight (body mass) is often perceived to influence his/her movements and actions, though empirical research appraising its influence has tended to focus upon physiological or biomechanical qualities (Walilko et al., 2005; Smith, 2006).

Given the recognised impact of confounding influences in other combat sports (Bridge et al., 2011; Ferreira et al., 2013) it seems plausible that 'situational' (independent) variables such as the contest outcome, weight class, ability and ring size would yield disparate technical performances in amateur boxing. Contest outcome aside, limited evidence exists that, for example, heavier boxers perform fewer actions overall than lighter boxers, or that smaller ring sizes increase the offensive and defensive demands during bouts. Moreover, research in team sports (Taylor et al., 2008; Lago, 2009; Lago et al., 2010; Sampaio et al., 2010a; Sampaio et al., 2010b) has revealed the existence of interactive effects between independent variables suggesting that such circumstances might apply also in amateur boxing. Indeed, it is plausible that, for example, progression from a novice to national standard of competition might be characterised by disparate technical demands pending the weight class of the boxer and so valid appraisals of performance ought to reflect the specific contest conditions beyond a single independent variable. The purpose of this investigation was to therefore analyse the technical demands of competitive amateur boxing according to the independent and interactive effects of contest outcome, weight class and standard of competition. 


\section{Methods}

\subsection{Participants}

With institutional ethics approval, observational research involving 92 English amateur boxers from 46 contests (mean \pm SD; age: $22.3 \pm 3.9$ y; body mass: $67.2 \pm 13$. kg; previous contests $25 \pm 16$ bouts) was undertaken. Boxers provided written informed consent for their contest to be recorded and analysed. The performances were distributed across all 10 weight classes and grouped as 'light (46 - $60 \mathrm{~kg}$ [ $n=22])$, 'middle' $(60-75 \mathrm{~kg}[n=48])$ or 'heavy' (>75 kg [ $n=22]$ ) boxers, two contest formats (six-minute bouts [ $n=56]$ : 3x2 min, and nineminute bouts [ $n=36]$ : 3x3 min, with rounds of both formats interspersed with one-minute rest intervals), three different sized square contest rings (4.9 [ $n=18], 5.5[n=40]$ and 6.1 [ $n$ $=34] \mathrm{m}^{2}$ ), and regional and national standard competition (referred to as novice $[n=56]$ and open class $[n=36]$ boxers, respectively) (Table 1). Regional level boxing consisted of interclub contests whereas national level bouts were those contested within the 'elite' national championships (Amateur Boxing Association of England, 2007).

Table 1. The number of performances according to the bout outcome, weight group and standard of competition.

\begin{tabular}{cccc}
\hline & & & $n$ \\
\hline Win & Light & Regional & 4 \\
Win & Middle & Regional & 17 \\
Win & Heavy & Regional & 7 \\
Win & Light & National & 7 \\
Win & Middle & National & 7 \\
Win & Heavy & National & 4 \\
Lose & Light & Regional & 4 \\
Lose & Middle & Regional & 17 \\
Lose & Heavy & Regional & 7 \\
Lose & Light & National & 7 \\
Lose & Middle & National & 7 \\
Lose & Heavy & National & 4 \\
\hline
\end{tabular}




\subsection{Procedures}

The contests were recorded with two digital cameras (Canon MV700, Japan) from adjacent sides, perpendicular to the boxing ring and subject to post-contest video analysis. Analysis was undertaken by the lead author who has extensive experience of boxing (former amateur boxer $[\approx 14$ years], coaching $[\approx 5$ years $]$ ) and performance analysis (6 years), using the Dartfish TeamPro software (version 4.0, Switzerland).

\subsection{Performance analysis template}

For an in-depth description of the performance analysis template, the reader is referred to Thomson, Lamb and Nicholas (2013). The template included eight attacking (attack frequency, total punches, jab, rear hand cross, lead hook, rear hook, lead uppercut, rear uppercut) and four defensive actions (defence frequency, arm, trunk and foot defences). Each offensive and defensive action was further notated with regard to its intended target (head, body) and outcome (successful, unsuccessful) based upon the level of contact between the punches thrown and the opponent's target area. The intra- and inter-observer reliability of the performance analysis template has been extensively assessed previously and found to be acceptable (Thomson et al., 2013).

\subsection{Data analysis}

The independent and interactive effects of contest outcome ('win', 'lose'), weight ('light', 'middle', 'heavy') and standard of competition ('regional', 'national') were determined using log-linear and logit modelling (Taylor et al., 2008; Tabachnick and Fidell, 2013) where the behavioural frequencies and associated outcomes were determined. Moreover, the comparison between ability groups was synonymous with distinct ring sizes and contest durations such that all regional contests were competed within $4.9(n=14)$ or $5.5 \mathrm{~m}^{2}(n=42)$ 
rings over three, 2-minute rounds, whereas all national standard contests were held within a $6.1 \mathrm{~m}^{2}(n=36)$ ring over three, 3-minute rounds; such situational conditions are characteristic of progression from novice to national standard boxing. All data satisfied concerns regarding independence, the ratio of cases to variables and expected cell frequencies (Tabachnick and Fidell, 2013) though zero values were recorded for the lead and rear uppercuts in 15 and 10 performances, respectively. Owing to the application of the geometric mean, such performances were therefore omitted from the analysis (O’Donoghue, 2013) resulting in samples of 77 and 82 for these actions.

Beginning with a saturated model (i.e. outcome $\mathrm{x}$ weight $\mathrm{x}$ ability interaction) and then employing a backward elimination process (Field, 2013), the simplest fitting model was identified by removing as many higher order associations and main effects as possible whilst maintaining adequate fit between the observed and expected cell frequencies (Tabachnick and Fidell, 2013). The resulting model therefore includes only those associations necessary to reproduce the observed frequencies. The likelihood ratio statistic was used to determine whether the expected frequencies produced by the model were not significantly $(P<0.05)$ different from the observed data.

Within the study the saturated, log-linear model was:

$$
\begin{gathered}
F_{i j k} \\
(\dot{\zeta})=\theta+\lambda_{i}^{O}+\lambda_{j}^{W}+\lambda_{k}^{A}+\lambda_{i j}^{O W}+\lambda_{i k}^{O A}+\lambda_{j k}^{W A}+\lambda_{i j k}^{O W A} \\
\ln \dot{\zeta}
\end{gathered}
$$

where the natural log for the expected frequency for a given cell $\begin{gathered}(i j)^{2} \\ \ln _{i} i\end{gathered}$ was the geometric mean of all cell log frequencies ( $\theta i$ and the parameter estimates ( $\lambda i$ according to the 
outcome $(O)$, weight class $(W)$ and ability $(A)$. Positive and negative parameter estimates for each main effect and interaction remaining within the model indicate the extent model constants ( $\theta i$ increase or decrease, respectively. As parameter estimates equate to zero across categories of an independent variable (Taylor et al., 2008), they are presented for the winning and regional performances only, with the losing and national performance parameter estimates representing the additive inverse. Moreover, by taking the exponent of each parameter estimate a multiplicative factor was derived such that the change in behaviour frequency could be specified (Taylor et al., 2008). For example, a parameter estimate of -2 produces a multiplicative factor change of 0.14 , resulting in the cell frequency being $86 \%$ of the model constant of the contingency table. Model constants are presented as backtransformed means and parameter estimate are expressed as the percentage change from the constant (Hopkins et al., 2009). All analyses were undertaken using SPSS (Version 17.0; Chicago, IL). Statistical significance in all tests was set at $P \leq 0.05$.

\section{Results}

\subsection{The influence of contest outcome, weight class and ability on behavioural frequency.}

The three-way log-linear analysis produced final models that included main effects only, twoand three-way interactions (Table 2), suggesting the frequencies were dependent upon the situational variables. Specifically, the models concerning the total punches, jabs, lead uppercuts and trunk defences performed, retained all effects, indicating that the highest order interaction (outcome $\mathrm{x}$ weight $\mathrm{x}$ ability) was significant. There were also several performance indicators for which the two-way interactions (attacks launched, backhand cross, rear hook, foot defence) and main effects (attacks launched, lead hook, rear uppercut, defences performed, arm defence) were significant. 
Table 2. Resultant model fit parameters for the total frequency of performance indicators in amateur boxing according to the outcome (O), weight class (W) and ability (A).

\begin{tabular}{lcccr}
\hline & Model & Likelihood ratio & \multirow{2}{*}{ d.f. } & $P$-value \\
\hline Attacks launched & {$[\mathrm{A}]$} & 13.0 & 10 & 0.227 \\
Total punches & {$[\mathrm{O} * \mathrm{~W} * \mathrm{~A}]$} & 0.0 & 0 & 1.000 \\
Jab & {$[\mathrm{O} * \mathrm{~W}][\mathrm{W} * \mathrm{~A}]$} & 2.8 & 4 & 0.599 \\
Backhand cross & {$[\mathrm{O} * \mathrm{~A}]$} & 10.2 & 8 & 0.253 \\
Lead hook & {$[\mathrm{O}][\mathrm{A}][\mathrm{W}]$} & 6.7 & 7 & 0.462 \\
Rear hook & {$[\mathrm{O} * \mathrm{~W} * \mathrm{~A}]$} & 0.0 & 0 & 1.000 \\
Lead uppercut & {$[\mathrm{W}][\mathrm{A}]$} & 7.7 & 8 & 0.464 \\
Rear uppercut & {$[\mathrm{W}][\mathrm{A}]$} & 8.0 & 8 & 0.430 \\
$\begin{array}{l}\text { Defences } \\
\text { performed }\end{array}$ & {$[\mathrm{A}]$} & 13.9 & 10 & 0.177 \\
Arm defence & {$[\mathrm{O}][\mathrm{W} * \mathrm{~A}]$} & 3.5 & 5 & 0.622 \\
Trunk defence & {$[\mathrm{O} * \mathrm{~W} * \mathrm{~A}]$} & 0.0 & 0 & 1.000 \\
Foot defence & {$[\mathrm{O} * \mathrm{~W}]$} & 5.5 & 6 & 0.484 \\
\hline Retained interactions and main effects are enclosed within square brackets. For example, [O * \\
W] indicate a significant interaction between outcome and weight. & &
\end{tabular}

For the outcome variable (main effect), winning performance was associated generally with a high offensive output (attacks launched, total punches and backhand cross), but few arm and trunk defences (Table 3). Main effects for each weight grouping were somewhat sporadic though generally there were lower frequencies for the 'lighter' and 'middle' weight groups, with higher frequencies for the 'heavy' group. Consistently reduced frequencies were associated with regional boxing performance, with nine of 12 performance indicator frequencies being significantly lower than the model constant. Outcome-by-weight interactions typically involved higher frequencies for winning performances by 'lighter' boxers, lower frequencies for the 'middle' weight boxers, with little change from the model constant for winning 'heavy' boxers. Noteworthy once more was the influence of ability, such that regional performances by 'lighter' boxers were associated with significantly reduced 
action frequencies, though regional 'middle' and 'heavy' boxing both yielded four positive and one negative change from the model constant. Finally, there were several behaviours across each of the three-way interactions reflecting both positive and negative changes from the model constant with no apparent directional trend in the parameter estimates.

Table 3. Typical performance (95\% CI) and percentage change for the total frequency of performance indicators in amateur boxing according to the outcome, weight class and ability.

\begin{tabular}{|c|c|c|c|c|c|c|c|c|c|c|c|c|}
\hline Model effect & $\begin{array}{l}\text { Atta } \\
\text { cks } \\
\text { laun } \\
\text { ched }\end{array}$ & $\begin{array}{l}\text { Tota } \\
\text { l } \\
\text { pun } \\
\text { ches }\end{array}$ & Jab & $\begin{array}{l}\text { Back } \\
\text { hand } \\
\text { cross }\end{array}$ & $\begin{array}{c}\text { Lea } \\
\text { d } \\
\text { hoo } \\
\text { k }\end{array}$ & $\begin{array}{l}\text { Re } \\
\text { ar } \\
\text { ho } \\
\text { ok }\end{array}$ & $\begin{array}{c}\text { Lea } \\
\text { d } \\
\text { upp } \\
\text { ercu } \\
t \\
\end{array}$ & $\begin{array}{c}\text { Rea } \\
\text { r } \\
\text { upp } \\
\text { ercu } \\
\mathbf{t}\end{array}$ & $\begin{array}{c}\text { Defe } \\
\text { nces } \\
\text { perfo } \\
\text { rmed }\end{array}$ & $\begin{array}{c}\text { Ar } \\
\text { m } \\
\text { def } \\
\text { enc } \\
\text { e }\end{array}$ & $\begin{array}{c}\text { Tru } \\
\text { nk } \\
\text { def } \\
\text { enc } \\
\text { e }\end{array}$ & $\begin{array}{c}\text { Foo } \\
\mathbf{t} \\
\text { def } \\
\text { enc } \\
\text { e } \\
\end{array}$ \\
\hline Frequency & $\begin{array}{c}105 \\
(100- \\
109)\end{array}$ & $\begin{array}{c}183 \\
(171 \\
- \\
195)\end{array}$ & $\begin{array}{c}64 \\
(60 \\
- \\
68)\end{array}$ & $\begin{array}{c}39 \\
(37- \\
41)\end{array}$ & $\begin{array}{c}49 \\
(46 \\
- \\
51)\end{array}$ & $\begin{array}{c}23 \\
(20 \\
- \\
26)\end{array}$ & $\begin{array}{l}5 \\
(5- \\
6)\end{array}$ & $\begin{array}{c}8 \\
(7- \\
9)\end{array}$ & $\begin{array}{c}73 \\
(70- \\
77)\end{array}$ & $\begin{array}{c}35 \\
(33 \\
- \\
37)\end{array}$ & $\begin{array}{c}25 \\
(23 \\
- \\
27)\end{array}$ & $\begin{array}{r}16 \\
(15 \\
18)\end{array}$ \\
\hline
\end{tabular}

Percentage change from constant

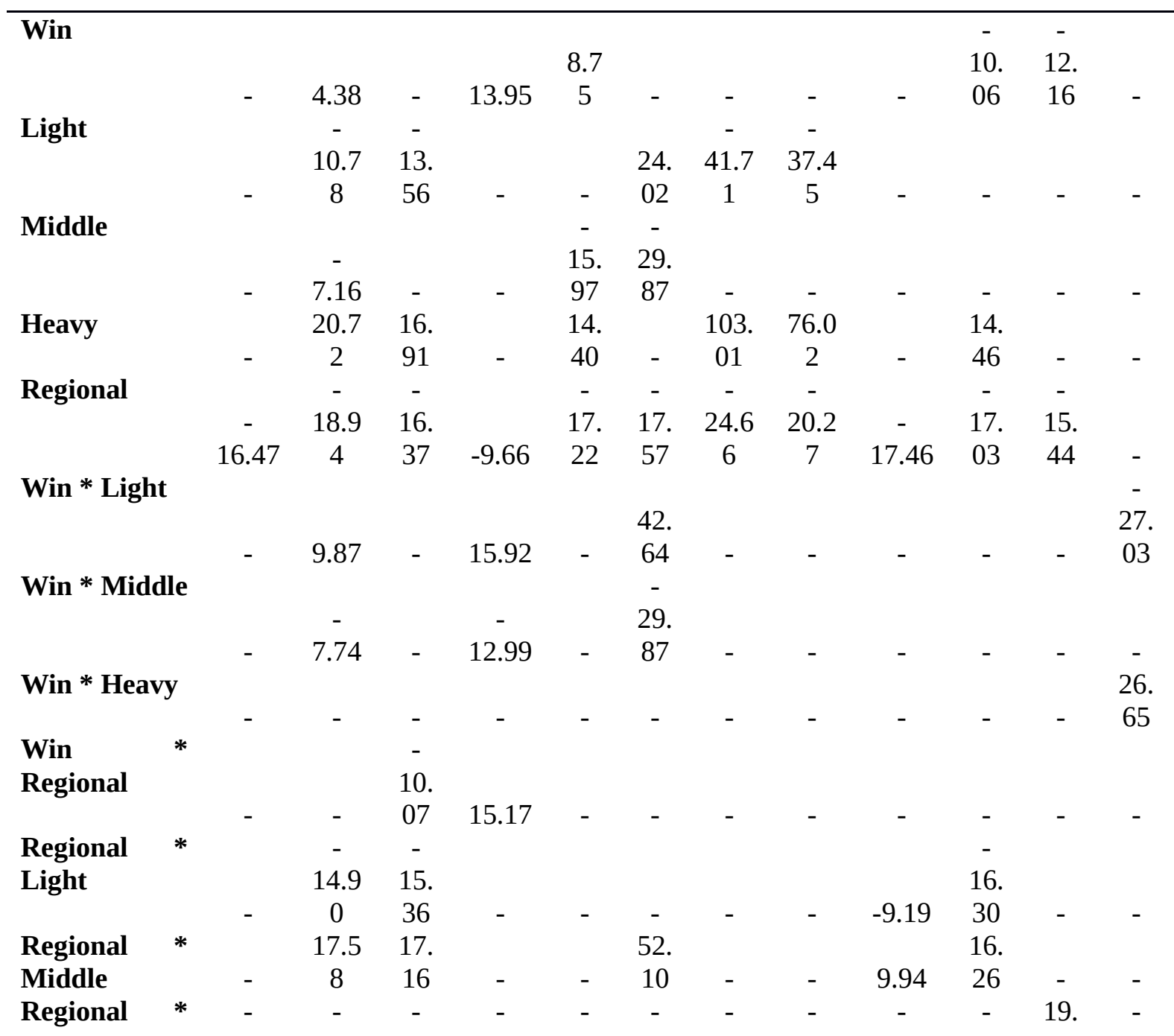


Win $\quad *$

Regional * 16.

Light

Win

Regional * 28.

Middle $\quad-6.98 \quad-\quad-\quad-\quad-\quad 82$

Win

Regional

22.

28.

Heavy

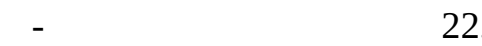

55

Note: Data is presented where parameter z-score was $>1.96$ thus indicating a significant change from the model constant (Tabachnick and Fidell, 2013). Given parameter estimates sum to zero across an independent variable, omitted values (e.g. national) are the additive inverse of those presented.

\subsection{The influence of contest outcome, weight class and ability on behavioural success}

Again, the models produced indicated that the frequencies of the successful actions were dependent upon main effects, two- and three-way interactions (Table 4). Specifically, the models for the arm and trunk defences retained all effects, signifying the highest order interaction (outcome $\mathrm{x}$ weight $\mathrm{x}$ ability) was significant. There were also several behaviours where two-way interactions (attacks launched, total punches, jab, rear hook, lead uppercut, foot defence) and main effects (attacks launched, backhand cross, lead hook, rear uppercut, defences performed) were significant.

Table 4. Resultant model fit parameters for the total frequency of successful performance indicators in amateur boxing according to the outcome $(\mathrm{O})$, weight class $(\mathrm{W})$ and ability $(\mathrm{A})$.

\begin{tabular}{lcccr}
\hline & Model & Likelihood ratio & \multirow{2}{*}{ d.f. } & $P$-value \\
\hline Attacks launched & {$[\mathrm{O}][\mathrm{W} * \mathrm{~A}]$} & 4.9 & 5 & 0.424 \\
Total punches & {$[\mathrm{O} * \mathrm{~W}]\left[\mathrm{W}^{*} \mathrm{~A}\right]$} & 3.3 & 3 & 0.348 \\
Jab & {$[\mathrm{O}][\mathrm{W} * \mathrm{~A}]$} & 4.6 & 5 & 0.470 \\
Backhand cross & {$[\mathrm{O}][\mathrm{W} * \mathrm{~A}]$} & 5.1 & 5 & 0.401 \\
Lead hook & {$[\mathrm{O}][\mathrm{A}]$} & 12.0 & 9 & 0.211 \\
Rear hook & {$[\mathrm{O} * \mathrm{~W} * \mathrm{~A}]$} & 0.0 & 0 & 1.000 \\
Lead uppercut & {$[\mathrm{W}]$} & 5.1 & 9 & 0.825 \\
Rear uppercut & {$[\mathrm{W} * \mathrm{~A}]$} & 6.3 & 6 & 0.394
\end{tabular}


Defences performed

Arm defence

$$
[\mathrm{O} * \mathrm{~W} * \mathrm{~A}]
$$

0.0

Trunk defence

For the frequency of successful actions, only two models (arm and trunk defence) retained significant parameter estimates within higher-order (three-way) interactions; the direction of such estimates did not follow a consistent pattern (Table 5). In terms of two-way interactions, regional-by-light performance was associated with negative parameter estimates and thus decreased frequencies, whereas regional-by-middle performance was related to positive parameter estimates. Outcome-by-weight interactions were largely inconsistent in producing either positive or negative parameter estimates. However, main effects for winning performance were invariably positive for several offensive actions, negative for 'light' and 'middle' performances, though positive for those of the 'heavy' group. Finally, with respect to the influence of ability, several parameter estimates were again negative, inferring lower frequencies compared to those associated with the model constants.

Table 5. Typical performance (95\% CI) and percentage change for the frequency of successful performance indicators in amateur boxing according to the outcome, weight class and ability.

\begin{tabular}{|c|c|c|c|c|c|c|c|c|c|c|c|c|}
\hline Model effect & $\begin{array}{c}\text { Att } \\
\text { ack } \\
\text { s } \\
\text { lau } \\
\text { nch } \\
\text { ed }\end{array}$ & $\begin{array}{c}\text { Tot } \\
\text { al } \\
\text { pu } \\
\text { nch } \\
\text { es }\end{array}$ & Jab & $\begin{array}{c}\text { Bac } \\
\text { kha } \\
\text { nd } \\
\text { cros } \\
\text { s }\end{array}$ & $\begin{array}{c}\text { Lea } \\
\text { d } \\
\text { hoo } \\
\text { k }\end{array}$ & $\begin{array}{c}\text { Rea } \\
\mathbf{r} \\
\text { hoo } \\
\mathbf{k}\end{array}$ & $\begin{array}{c}\text { Lea } \\
\text { d } \\
\text { upp } \\
\text { erc } \\
\text { ut }\end{array}$ & $\begin{array}{c}\text { Rea } \\
\text { r } \\
\text { upp } \\
\text { erc } \\
\text { ut }\end{array}$ & $\begin{array}{c}\text { Defe } \\
\text { nces } \\
\text { perf } \\
\text { orm } \\
\text { ed }\end{array}$ & $\begin{array}{c}\text { Ar } \\
\text { m } \\
\text { def } \\
\text { enc } \\
\text { e }\end{array}$ & $\begin{array}{c}\text { Tru } \\
\text { nk } \\
\text { def } \\
\text { enc } \\
\text { e }\end{array}$ & $\begin{array}{c}\text { Foot } \\
\text { defen } \\
\text { ce }\end{array}$ \\
\hline Frequency & $\begin{array}{c}44 \\
(40- \\
47) \\
\end{array}$ & $\begin{array}{c}57 \\
(52 \\
- \\
63) \\
\end{array}$ & $\begin{array}{c}18 \\
(17 \\
-19)\end{array}$ & $\begin{array}{c}13 \\
(12- \\
14)\end{array}$ & $\begin{array}{c}15 \\
(14- \\
16)\end{array}$ & $\begin{array}{c}8 \\
(7- \\
9) \\
\end{array}$ & $\begin{array}{l}3 \\
(3- \\
4)\end{array}$ & $\begin{array}{c}4 \\
(4- \\
5)\end{array}$ & $\begin{array}{c}35 \\
(33- \\
36) \\
\end{array}$ & $\begin{array}{c}16 \\
(15 \\
- \\
17)\end{array}$ & $\begin{array}{c}17 \\
(16- \\
19)\end{array}$ & $\begin{array}{c}11 \\
(10- \\
12)\end{array}$ \\
\hline
\end{tabular}

Percentage change from constant

\begin{tabular}{|c|c|c|c|c|c|c|c|c|c|c|c|c|}
\hline \multirow[t]{2}{*}{ Win } & 16.1 & 19. & 20. & 38.3 & 21. & & & & & & & \\
\hline & 4 & 27 & 64 & 9 & 22 & - & - & - & - & - & - & - \\
\hline \multirow[t]{3}{*}{ Light } & - & - & & & & & & & & & & \\
\hline & 15.2 & 18. & & & & & & & & & & \\
\hline & 5 & 92 & - & - & - & - & - & - & - & - & - & - \\
\hline Middle & & - & - & - & - & - & - & - & - & - & - & - \\
\hline
\end{tabular}




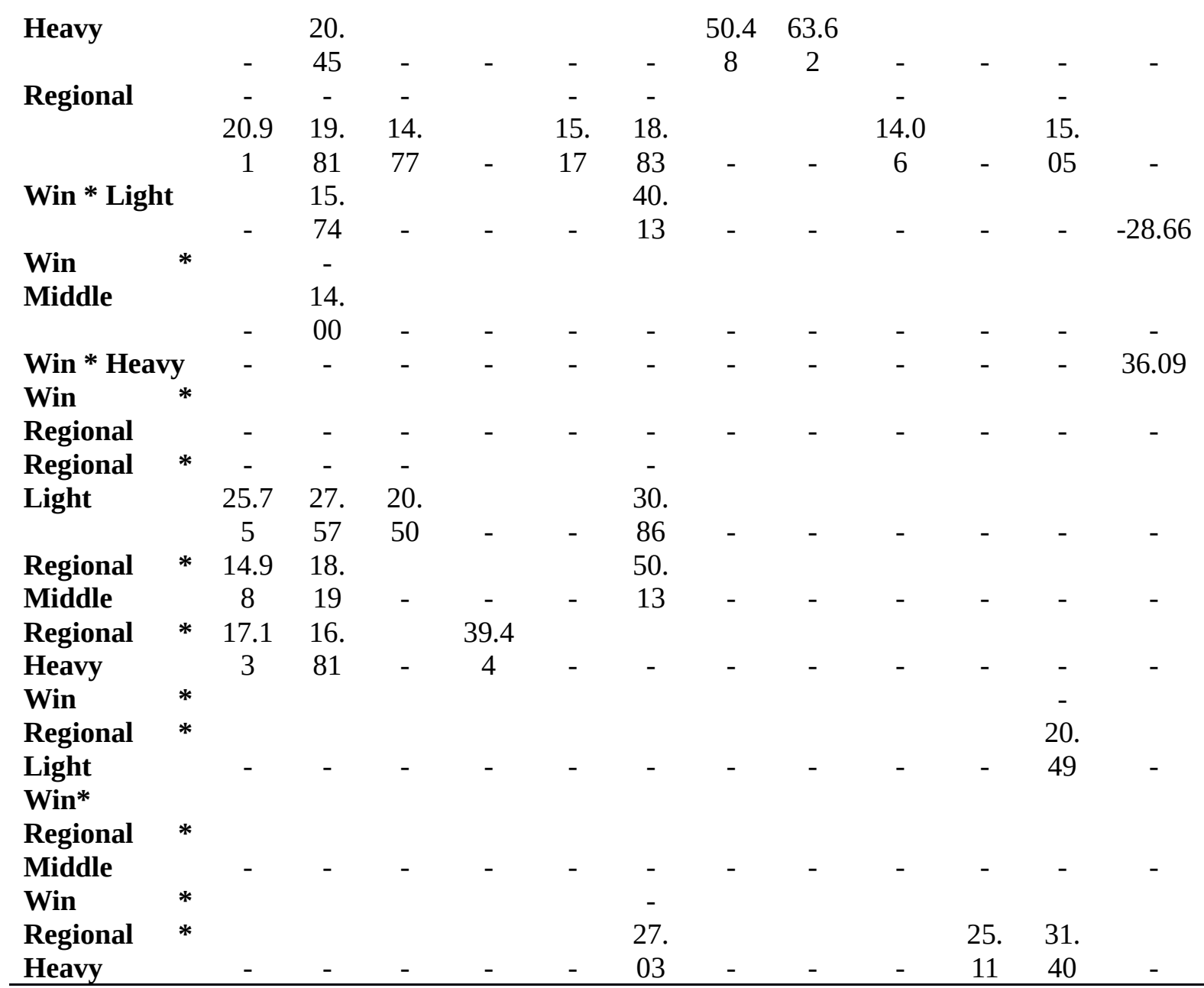

Note: Data is presented where parameter z-score was $>1.96$ thus indicating a significant change from model constant (Tabachnick and Fidell, 2013). Given parameter estimates sum to zero across an independent variable, omitted values (e.g. national) are the additive inverse of those presented.

\section{Discussion}

Collectively, the analyses described above provide original data with respect to the technical characteristics of amateur boxing and the independent contributions of weight class and ability level to contest outcome, and the interactions between independent variables. Similar to observations in team sports, the emergence of several significant two- and three-way interactions highlight that performance in the individual sport of boxing also takes place within a complex environment (Lago, 2009; Lago et al., 2010; Sampaio et al., 2010a; Sampaio et al., 2010b) that should be considered in future evaluations of the technical demands of amateur boxing. 
Independent of the situational variables, offensive technical performance for bouts was typified by 105 (95\% CI: 100-109) individual attacks and 183 (95\% CI: 171-195) punches, and thereby indicative of brief attacks, each involving few punches. Of the punches performed, the jab was the most frequent despite it being the least successful (i.e. jab success/jab frequency $=18 / 64=28 \%$ success $)$. This punch is posited as being the most important type as it possesses injurious potential whilst setting up more forceful attacks (Hickey, 2006), and has the lowest delivery time, allowing an opponent less time to defend (Piorkowski et al., 2007). Following the jab, the rear hand cross, lead and rear hooks were the punches thrown most frequently; approximately a third of these were landed successfully (33 - 40\% success). These punches are typically thrown to cause injury and/or affect judging decisions and are known to generate higher peak forces at impact than the jab (Hickey, 2006; Smith et al., 2000). As observed in previous research (El-Ashker, 2011; Davis et al., 2013, 2015a, 2015b), the lead and rear uppercuts were performed the least frequently, possibly because they necessitate the shortest distance between a boxer and the target (Hristovski et al., 2006) and throwing an uppercut might therefore afford the opponent more opportunities to counter-attack given the boxer performing the punch would be within his/her range (arm length). With respect to defensive actions, a preference for using the arms was established, followed by trunk and foot defences. Interestingly though, the most effective form was the use of foot defences (as 70\% were deemed successful) probably owing to their action of typically moving the boxer out of the opponent's range of punching, whereas trunk and arm defences require the boxer to remain within range (Hickey, 2006).

Log-linear analysis revealed the outcome of a boxing contest was influenced by the frequencies of eight of twelve behaviours. Generally, winning performance was characterised 
by an overall higher (than model constants) number and success of offensive actions, alongside fewer defences using the arm and trunk. The present data suggests high offensive output relative to the opponent remains an important facet of successful performance and the development of a 'positive' impression might have led judges to award points (via their computerised scoring) more readily to a particular boxer, alongside the higher probability that performing more offensive actions increased the likelihood of landing a scoring blow and, ultimately, winning a bout. Moreover, the efficiency (ratio of actions performed to those deemed successful) of many performance indicators was higher in winning boxers. This strengthens the supposition that the computer-based point scoring system placed emphasis also upon the quality of a boxer's actions. Consequently, technical mastery of such skills (i.e. jab, rear hand cross, lead hook) should be a priority for boxers competing under computerbased judging.

Anecdotally (amongst coaches and boxers) and empirically in the form of physiological (Khanna and Manna, 2006) and biomechanical (Walilko et al., 2005) assessments it is considered that features of boxing performance differ between weight classes. The current performance analysis has provided new evidence that weight class also influences the frequencies of nine performance indicators, and ten performance indicators with respect to the success of the actions, but in an inconsistent and perhaps unexpected manner. For example, whilst it is perceived that boxers' overall activity rates typically decrease with increasing body mass, our data contradict this since higher activity (frequency of actions) rates were often observed in the heavier weight classes than the middle and light weights. Importantly, coaches and boxers should be cautioned against prescribing training and appraising performance based upon a boxer's weight class alone. Instead, they need to be 
aware of the roles played by situational factors (Lago et al., 2010) such as those identified here, particularly ability level.

Ability had the foremost impact upon performance, influencing the frequency and success of eleven performance indicators, respectively. Regional-level bouts of six-minute duration were associated with lower offensive and defensive outputs than national standard bouts competed over nine minutes. That boxers competing in shorter bouts experienced lower external demands seems logical and from this perspective, boxers competing in different contest formats require individualised training sessions in preparation for the demands of each. Moreover, those transitioning between formats should be cognizant of the expected changes in technical performance (i.e. increased frequency of actions in longer duration bouts). Assuming the absolute external demand is reflective of the internal physiological load experienced (Akubat et al., 2013) boxers performing over nine minutes are likely to require a higher level of aerobic conditioning (Chaabène et al., 2015). Additionally, as the ability groups are synonymous with different ring dimensions $\left(4.9\right.$ and $5.5 \mathrm{~m}^{2}$ versus $6.1 \mathrm{~m}^{2}$ for regional and national, respectively), this is a further source of variation in terms of internal and external demands and warrants investigation.

Despite the current study providing the most comprehensive analysis of amateur boxing performance to-date, it is acknowledged that there are limitations to its thoroughness. Firstly, there is the unquantified effect of the interaction between the two boxers, and in particular their boxing styles. It seems rational that a contest between a 'counterpuncher' and an 'aggressive fighter' compared to a bout between two 'counter-punchers’ would yield different demands (Hickey, 2006). Future research ought to therefore objectively define boxing styles 
and explain their influence on the technical demands, adding further specificity to a boxer's preparations and competitive strategies. Secondly, when appraising three-way interactions, the division of the sample into 12 groups meant the lightweight performances of regional standard and heavyweight contests of national standard were represented by four performers. Given the requirement for an adequate sample size to detect meaningful differences in the presence of variability (Batterham and Atkinson, 2005), future research of this kind should seek to contain larger samples of boxers.

Still, the results of this study should facilitate coaches' and boxers' understanding of the performance according to the contest conditions (Lago et al., 2010; Sampaio et al., 2010a) and are advised to use the information from this analysis to inform their approach to training and competition. Moreover, within competition boxers ought to adopt an offensive strategy (relative to the opponent) in order to maximise the probability of success. In contrast, conditioning and competitive strategies should not be influenced by a boxer's body mass. However, training does need to accommodate the distinctive demands of regional and national levels of competition given the disparate work-to-rest periods involved. The findings are also of interest to those inclined to interpret the technical demands of the sport (e.g. coaches and sport scientists) (Lago et al., 2010; Sampaio et al., 2010b) as valid appraisals of performance ought to consider not only the contest outcome, but also the standard of competition and thus the work-to-rest ratios and ring dimensions adopted during bouts. Future research considering other situational variables might add further specificity to boxers’ preparation and competitive strategies.

\section{References}


Akubat, I., Barrett, S. and Abt, G. (2013), Integrating the internal and external training load in soccer. International Journal of Sports Physiology and Performance, 9(3), 457462.

Amateur Boxing Association of England. (2007), Rules and regulations of amateur boxing. Barnsley, U.K.: Hot Metal Press.

Batterham, A.M. and Atkinson, G. (2005), How big does my sample need to be? A primer on the murky world of sample size estimation. Physical Therapy in Sport, 6, 153-163.

Bianco, M., Loosemore, M. and Daniele, G. (2013), Amateur boxing in the last 59 years. Impact of rules changes on the type of verdicts recorded and implications on boxers' health. British Journal of Sports Medicine, 47, 452-457.

Bridge, C.A., Jones, M.A. and Drust, B. (2011), The activity profile in international taekwondo competition is modulated by weight category. International Journal of Sports Physiology and Performance, 6, 344-357.

Chaabène, H., Tabben, M., Mkaouer, B., Franchini, E., Negra, Y., Hammami, M., et al. (2015), Amateur boxing: Physical and physiological attributes. Sports Medicine, 45(3), 337-352.

Davis, P., Wittekind, A. and Beneke, R. (2013), Amateur boxing: Activity profile of winners and losers. International Journal of Sports Physiology and Performance, 8, 84-91.

Davis, P., Benson, P., Pitty, J., Connorton, A. and Waldock, R. (2015a), The activity profile of elite male amateur boxing. International Journal of Sports Physiology and Performance, 10(1), 53-57.

Davis, P., Benson, P. R., Waldock, R. and Connorton, A. J. (2015b), Performance analysis of elite female amateur boxers and comparison to their male counterparts. International Journal of Sports Physiology and Performance. Advance online publication. doi: 10.1123/ijspp.2014-0133

El-Ashker, S. (2011), Technical and tactical aspects that differentiate winning and losing performances in boxing. International Journal of Performance Analysis in Sport, 11, 356-364.

Ferreira, J., Panissa, V. L. G., Miarka, B., Takito, M. Y. and Franchini, E. (2013), Home advantage in judo: A study of the world ranking list. Journal of Sports Sciences, 31(2), 212-218.

Field, A. (2013), Discovering statistics using IBM SPSS statistics ( $4^{\text {th }}$ ed.). London: Sage.

Hickey, K. (2006), Boxing: amateur boxing association coaching manual. Worthing, West Sussex: Littlehampton Book Services Ltd.

Hopkins, W., Marshall, S., Batterham, A. and Hanin, J. (2009), Progressive statistics for studies in sports medicine and exercise science. Medicine and Science in Sports and Exercise, 41(1), 3.

Hristovski, R., Davids, K., Araujo, D. and Button, C. (2006), How boxers decide to punch a target: Emergent behaviour in nonlinear dynamical movement systems. Journal of Sports Science and Medicine, Combat Sport Special Issue, 60-73.

Khanna, G.L. and Manna, I. (2006), Study of physiological profile of Indian boxers. Journal of Sports Science and Medicine, 5, 90-98.

Lago, C. (2009), The influence of match location, quality of opposition, and match status on possession strategies in professional association football. Journal of Sports Sciences, 27(13), 1463-1469.

Lago, C., Casais, L., Dominguez, E. and Sampaio, J. (2010), The effects of situational variables on distance covered at various speeds in elite soccer. European Journal of Sport Science, 10(2), 103-109.

O’Donoghue, P. (2007), Reliability issues in performance analysis. International Journal of Performance Analysis in Sport, 7(1), 35-48. 
O'Donoghue, P. (2013), Statistics for sport and exercise studies: An introduction. United Kingdom: Routledge.

Piorkowski, B., Lees, A. and Barton, G.J. (2011), Single maximal versus combination punch kinematics. Sports Biomechanics, 10(1), 1-11.

Sampaio, J., Drinkwater, E. J. and Leite, N. M. (2010a), Effects of season period, team quality, and playing time on basketball players' game-related statistics. European Journal of Sport Science, 10(2), 141-149.

Sampaio, J., Lago, C., Casais, L. and Leite, N. (2010b), Effects of starting score-line, game location, and quality of opposition in basketball quarter score. European Journal of Sport Science, 10(6), 391-396.

Smith, M.S. (2006), Physiological profile of senior and junior England international amateur boxers. Journal of Sports Science and Medicine, Combat Sports Special Issue, 7489.

Smith, M.S. and Draper, S. (2007), Amateur boxing. In E.M. Winter, A.M. Jones, R.C.R.

Davison, P.D. Bromley and T.H. Mercer (Eds.) Physiology testing guidelines (pp. 155-159). Cornwall, U.K.: Routledge.

Smith, M.S., Dyson, R.J., Hale, T. and Janaway, L. (2000), Development of a boxing dynamometer and its punch force discrimination efficacy. Journal of Sports Sciences, 18(6), 445-450.

Tabachnick, B.G. and Fidell, L.S. (2013), Using multivariate statistics: Pearson new international edition. United Kingdom: Pearson.

Taylor, J. B., Mellalieu, S. D., James, N. and Shearer, D. A. (2008), The influence of match location, quality of opposition, and match status on technical performance in professional association football. Journal of Sports Sciences, 26(9), 885-895.

Thomson, E., Lamb, K. and Nicholas, C. (2013), The development of a reliable amateur boxing performance analysis template. Journal of Sports Sciences, 31(5), 516-528.

Walilko, T., Viano, D. and Bir, C. (2005), Biomechanics of the head for Olympic boxer punches to the face. British Journal of Sports Medicine, 39(10), 710-71. 